\title{
Ethics of Care among TVET Schools' Principals: Is It Reflected?
}

\author{
Prakash C Bhattarai, PhD \\ Associate Professor, Head- Department of Development Education, \\ Kathmandu University-School of Education, \\ Hattiban, Lalitpur, Nepal \\ Email for correspondence: prakash@kusoed.edu.np ; prakash.c.bhattarai@gmail.com
}

\begin{abstract}
Ethics of care, a paradigm for mutual respect, compassion and attention to others in an organization, is considered as the most indispensable and unavoidable for a workplace. Particularly, it is essential in TVET schools as the students are mostly from diverse cultural, family and learning backgrounds and many of them require emotional and psychological support. However, TVET schools are often blamed as care within the schools is yet to be reflected in practice. In this context, a case study was carried out using humanistic paradigm to examine the nature and gravity of ethics of care in TVET schools in Nepal. Data were collected/generated from five TVET schools through prolonged interview by using interview protocol. The data were then analyzed and interpreted with relevant literature and personal reflection. This finding shows that care is imperative to lessen the anxiety and handle the complexities with the students. Care is communicated through language, actions and behaviors. In this regard, the principal maintains a comfortable channel of communication and interacts with the stakeholders to maintain care. However, each principal is unique in their approach of ethics of care. In this context, a discourse or research to explore the differences among the approaches of the principals help them learn from each other.
\end{abstract}

Keywords: Ethics of Care, Care in TVET Schools, Nepali TVET Schools, TVET School Leadership

\section{Context of TVET Schools}

In Nepal, TVET (Technical and Vocational Education and Training) had begun since long. However, the planed efforts of establishing TVET activities were emphasized after democracy was introduced in Nepal in 1951. At present, the TVET providers of Nepal consist of Council for Technical Education and Vocational Training (CTEVT), Tribhuvan University
(TU), Kathmandu University (KU), BP Koirala Institute of Health Sciences, and National Academy for Medical Science (NAMS), Department of Cottage and Small Industries (DCSI) under the Ministry of Industry Commerce and Supplies, the Vocational and Skill Development Training Academy (VSDTA) under the Ministry of Labor Employment and Social Security, Nepal Academy of Tourism and Hotel 
Management (NATHM) under the Ministry of Culture, Tourism and Civil Aviation, etc. Out of these TVET providers, the major TVET national enrolment capacity lies with CTEVT. It was obvious as the trend of establishing vocational institutions grew in number that demanded strategic planning and implementation on the part of government (Sharma, 2006). To address the needs, the Council for Technical Education and Vocational Training Act, 1988 (amended in 1993, 2006, 2010) was passed, which eventually established the Council for Technical Education and Vocational Training (CTEVT) (GON, 1988). This national umbrella organization was tasked with formulating TVET policies, coordinating programs, developing and expanding TVET and ensuring quality of TVET in the country under the CTEVT Act, 1988 and TVET policy, 2012.

Nevertheless, the TVET subsector has always been subject to uncoordinated and haphazard ways of operation (Khanal, 2013) which has consequently affected the ethical environment of knowledge production, management, and distribution in these schools. In the long run, this situation obstructs the ethical development of graduates who will be contributors to ethically sound and constructive climates in their future workplaces (Fan, 2011).

When the ethics within TVET schools come into consideration, ethics of care of all stakeholders such as principals, instructors, teachers, etc. is pertinent. Out of them, ethics of care of principals is imperative to ensure that leadership in school was welcoming and responsive to the students and showed kindness, considerations, and positive emotions. Eventually, on one hand, this brings a trust and harmony in a workplace while on the other hand, it cultivates ethics of care to the learners so that they can demonstrate their love and caring in future workplace. Consequently, it brings sustainable development to the organization and people where they work (Shapiro \& Stefkovich, 2011). Therefore, the nature and gravity of care in TVET organizations have been explored through a study and have been presented in the following sections. In the beginning, the paradigm of the ethics of care has been examined.

\section{Paradigm of Ethics of Care in Principals}

The paradigm of ethics of care has been derived from the theory of relational ethics. The core elements of relational ethics are identified as engagement, mutual respect, embodied knowledge, and attention to an interdependent environment. These elements were informed by the concepts of "interdependency, relational personhood, authentic dialogue, and the importance of community" (Austin, 2006, p. 136). The idea of ethics of care have been established through the same line of caring as others who are in need of it.

Starratt (1991) stated that "earlier discussions of the ethic of justice took place in a theological context; more recent discussions have tended to ground the ethics of love and caring philosophy" (p. 195). The philosophy has its roots in the research of three major authors: Lowrence Kohlberg, Carol Gilligan and Nel Noddings who developed the concept in the form of ethics of caring.

The foundation of the ethics of care began with Gilligan's critique of Kohlberg's research. Kohlberg began his theory of moral development stage in 1955 with his doctoral dissertation proposal. The ethics of care was born when Carol Gilligan criticized Kohlberg's theory and offered a definition of ethics different from Kohlberg's in the resolution of moral dilemmas. For Gilligan (1982), the ethics of care included concepts of being there, listening, understanding, sharing responsibility for another's welfare, strengthening and maintaining relationships, attachment, and abandonment of relationships. She wrote about the differences by which men and women approach moral issues. She clarified that women tend to engage in actions that preserve and honor human relationships and demonstrate care for those they feel responsible for. In contrast, men tend to seek solutions by applying abstract rules of justice. Gilligan also found that females turned more often to 'caring' when responding to ethical dilemmas 
than males, who tended to solve the same dilemmas using the lens of justice. Women and girls frequently turned to another voice that of care, concern, and connection, in finding answers to their moral dilemma. Noddings (2002) offered a similar view to that of Gilligan. However, her focus has always been on the approach of the mother which she called the feminine voice. Her argument starts from the position that care is basic in human life and that all people want to be cared for. For her, the four major components for nurturing the ethics of care include modeling, dialogue, practice, and confirmation. Therefore, she thinks that teachers ought to show students ways to care and engage them in dialogue about moral life. Moreover, teachers ought to engage themselves to supervise their practice in caring, and confirm them in developing their best selves. Starratt (1991) identified that "an ethic of care relates to the fundamental requirements of interpersonal relations, not from a contractual or legal standpoint but in terms of absolute respect" (p. 195). Langlois (2011) also considers human relations and welfare to be of major importance for the proper functioning of organizations. She emphasized the need of harmonious social relations for the management with people but not management of people. Additionally, Langlois (2011) believed that policies formulated considering the individuals within the organization and their designations express care for others. She stated that an organization practicing an ethic of care helps to promote interpersonal relations, quality of life at work, health of workers, and health of the community of workers. This idea seems relevant in the context of Nepal.

Ethic of care is not free from limitations. Langlois (2011) pointed out the limitations and their solutions. She believed that it can be challenging to announce a decision that may hurt someone or may be a source of concern. For example, a manager who knows that an employee is in the middle of a difficult personal situation might hesitate to share complaints from other colleagues about the person's performance at work. Familiarity between people can also make it hard to view situations in a more global manner.
Such limitations can, however, be overcome by applying the other two forms of ethics, critique and justice.

Ethics of care gives a framework to decide our action and shows the consequences of our decision and action. It makes us think about the individuals benefitted and hurt from the leader's decision, the long-term effects of the decision made and the way individuals pay back in the future for the help they get at present (Shapiro \& Stefkovich, 2011). Overall, this paradigm guides a school leader to make decisions with values in mind such as loyalty and trust. It does not only explain the principles of respect in the workplace but also provides a sense of love and compassion for each other.

\section{Case Study: My Way of Exploration}

I got two distinct philosophical foundations of case study literatures: post-positivists and humanistic. Some critics have suggested that Yin's research has been situated within a post-positivist paradigm, whereas Merriam's and Stake's approach have been non-positivist (Boblin, Ireland, Kirkpatrick, \& Robertson, 2013; Brown, 2008). I used Merriam (1998) and Stake (2005) in this study considering multiple perspectives to examine ethics of care. However, this does not mean that I did not use Yin (2014). I got several guidelines from Yin's case study methods. For example, case selection guideline was considered through Yin (2014).

Data were collected/generated from five TVET schools through case study protocol but it was not structured and dedicated to confirm/disconfirm knowledge. The protocol was simply a guideline to generate information in the phase of case study. A prior interview was carried out to contextualize the protocol. The interview I chose for this study was "prolonged case study interview" (Yin, 2014, p. 110) with 2 to 4 sittings of approximately one to two hours each. During the interviews, I gave adequate opportunities for our research participants to express their opinions and each time I made attempts to be an empathic listener (Yin, 2011) and occasionally 
probed in order to delve more deeply into particular lines of thought or descriptions. At the end of each interview, I asked the research participant if he or she wanted to add any further comments. Upon getting back from the field, I jotted down those expressions of the participants that I failed to capture during interactions in the field. I coded their remarks when I felt difficult to note them down on the spot. I reflected my field experiences in the note and summarized them in the end. I also observed the characteristics of the individuals during the interview. Those observations of the study participants and their contexts provided me with some essential insights at the time when the phenomenon was being observed.

For the analysis purpose, I transcribed all the data generated from our field participants. The transcribed data were then edited with original record and the data were coded. The coded data were categorized to develop themes. During this study, I made the best efforts to maintain credibility at every stage of this research. Particularly, credibility was maintained through: (a) considering if there were credibility violation by means of our thinking and preset minds, (b) considering at our implementation strategies such as member checking, thick description, etc., (c) our critical and reflexive role during every stage of research process. I also made efforts to maintain ethics by not harming participants by any ways. For example, I conducted interviews in their leisure time and I gave pseudo name to all the participants in presenting their narration. After data were generated and analyzed, they were presented and interpreted into the headings of importance, communication and gravity of care. Then, meaning was sought under the heading of influence of caring in TVET schools: An ongoing phenomena.

\section{Importance of Caring in the Life of Principals}

The term care is defined as "the sense of loving, nurturing, tending and upbringing" (Vogt, 2002). The data analysis of this study also indicated that care in the context of school goes together with students' loving and nurturing needs. To address the needs, participants hold ample and strong evidences on how and why the school leaders (principals) under this study adopted "care" in their life of principals. In this context, Brahma Sharma (male, aged 55), a principal of TVET school, stated that ethics regarding care is imperative to the school principals because:

Some students in this school are from socially deprived, economically backward and poor peasant family. These children are mostly emotionally challenged, economically fragile and socially depressed... As a school principal, I think that my care towards them would help them to be emotionally sound, which would further help them participate in the learning processes creatively.

As said by the principal, this kind of caring attribute of the school leadership is imperative (Myers, 2013). The importance of administrative care was emphasized to ensure that leadership in school was welcoming and responsive to the students. Therefore, a nurturing environment in this context is the approach to communicate care in which students (disregarding their class, castes, gender, religion, etc.) may uncover their individual potential under the kindness, considerations, and positive emotions of the school leaders.

The principal's caring attitude and behaviors also help the students revitalize their emotional regulations, which, in turn, promote them to move towards academic success vigorously. This new dimension encouraged me to explore the role of care in fostering other dimensions. While enquiring, Rishi Baniya (male, aged 51), one of the principals, said, "Principals' care lessens the anxiety of the students." While describing the anxiety of the students the principal noted:

The students come to school from different family backgrounds. They are often anxious of the new environment of the school. They are also worried about the social relationship, academic performance and the challenges ahead which are unknown 
to them. My role in this context is to help them identify their challenges, course of action and the way to deal with the new school atmosphere in which they are supposed to perform.

The above narration shows that students are worried about their personal and academic life when they are new to the schools. Principles' caring in the context help the students to tackle the situation without much difficulty.

\section{Communication of Care in TVET Schools}

In the TVET schools where I based my research, students were admitted after grade 10. The environment for these newcomers in the schools is completely different from what they experience in their earlier schools. Particularly, in the new environment, a student often observes unfamiliarity to the circumstances in which $\mathrm{s} / \mathrm{he}$ is supposed to perform his/her action. One of the students named Biraj Adhikari of Diploma in engineering shared, In the early days, the context of this school was very unusual to me. For example, I had to live in the hostel, which I had never done before. I was involved in several whole day activities as per my daily schedule which was overburden to me.

This shows that the students require some new approaches to adapt themselves in the new environment, which they have never seen before. Schools' codes of conduct, the social relationship between the students and the school administration, and also the relationship among the students can be some approaches in this regard. However, students feel hard to adjust at first since they cannot perform their actions, behaviors and attitudes in accordance with the needs of those approaches. According to Rajan Thapa (male, aged 44), one of the principals under this study,

In the beginning, the students often find it difficult to identify and develop a new approach for coping with the problems that arise in the new environment, and they get anxious. Anxiety might lead to frustration, which further impedes his/her performance.

Phillips (1991) also said that care often tends to lessen the level of anxiety on the part of the students. It ensures the emotional well-being and regulates students' emotions in a right way. This recreates the congenial atmosphere within the school premises in which the students are encouraged to display better learning performance.

In many cases, the participants (principals) of the study approached such students with some micro level of psychosocial individual dealing aiming at lessening or removing the students' anxiety. In the context of this study, I aimed at exploring how the principals of technical schools under this study use "care" as a psychosocial tool as a part of their ethical leadership. In this regard I asked Brahma Sharma about the way he communicates care and love to the students studying in his school. In reply, he said, "Care needs to be communicated through language, actions and behaviors." His explanation regarding his action and behavior to communicate his "care" to the students is as follows:

I often tend to appear before students in an easy and comfortable way. They often find me easy to share their personal, social and academic concerns. I listen to them and show keen interest regarding their concerns. If needed, I deal with them individually. Individual dealing with students provides me with an opportunity to counsel them and help me identify their sufferings and give them solutions. I empathize with the pain and pleasure of my students. I also enquire about their concerns informally whenever they meet me at the corridor, dining hall, playground, etc. When they come back to the school hostel from home, I ask about their family. I often make them feel that I am behind them to assist in their hardships as far as possible.

The above quotation shows that there needs to be a 
congenial environment for students in a school where they can find easy access to their principal. The more amicable the principal becomes, the students find it easier to share their emotions. The parent-like counseling delivered by the principal plays a therapeutic role in redirecting the students' emotions and in building up their confidence. The students need a sound official (administrative) care to tie up their psychosocial and academic performances. This care helps them keep their fear and anxiety away. Informal interaction with the students by principals is the other way of communicating care. Informal interaction also opens grounds for a principal to discuss the personal and social concerns of the students. Discussion with students in natural setting (not official) helps the principal to communicate care and love in a more sustainable way. According to the participants, care can also be communicated imperceptibly by performing administrative responsibilities in the daily professional life. The purpose of care, in this concern, is to create enabling environment for achieving the better performance within the school premises.

The care of a school principal also becomes visible while settling arguments, disputes and conflicts that possibly take place between/among the students, teachers and administrative staff. Rishi Baniya (male, aged 51), one of the principals of a technical school, narrated an event of conflict in his school and his role in pacifying the conflict, in the following way: A student complained to me against an instructor time and again claiming that the instructor did not teach well; and that he often came out of the classroom to talk to his friends on the cell phone. After repeated complaints, I supervised the instructor and found him to be innocent. I then called the student and inquired why he had accused the instructor. I came to know that the family of the student had a dispute with the instructor on some social matter. The boy wanted to trouble the instructor as a part of revenge... I convinced him not to trouble the instructor. But he made a group of friends in the community to take revenge on the instructor. I, as a principal, called his parents and discussed about the questionable behavior of the boy. Later, the student realized his mistake and apologized for his wrong behaviors.

There can be a number of events of wrong deeds done by the students, instructors and the other staff of the schools. In some circumstances, a principal needs to forgive the wrong doers and provide them a chance to rectify their wrong behaviors and actions. The principal, in the data mentioned above, showed his care towards the guilty student as a part of his leadership. He listened to the student's complaints carefully. He also investigated to ensure whether the complaint was genuine. After finding out that the teacher was innocent, he counseled the student and made an effort to establish good relation between the instructor and the student. For this principal, making mistake is a natural phenomenon. He believes that it is wrong to take action against anyone for a remediable mistake. He claims that forgiveness is an essential attribute to communicate "love" and "care" to the students. It helps the principal in developing the sense of oneness, unity and respect among the students. This indicates that giving chance to improve behavior also begets honesty, dedication and trust towards the principal and the school as a whole. The boy, in the above anecdote, turned to be honest and loyal to the principal after being forgiven for his mistake

Care of the school leadership can justifiably take place if the principal of the school maintains an easy, comfortable and effective channel of communication within the school system. During the interviews with the principals under this study, I discussed the existing channel of communication to address the grievances of the concerned individual (students and non/teaching staff) in the schools. Bal Krishna Shrestha (male, aged 48 ) told me that the students make attempt to get their grievances addressed either by their class teacher or the committee head of the extra-curricular activities of the school. The principal 
told me, "If the grievances are serious, I personally involve myself in addressing them." For the principal, giving care to all contributes to establishing harmony and developing the sense of "acceptance" among the school family members. The principal assured that he was to arrange for a complaint box through which he would collect the complaints and grievances of the instructors and students. He also importantly emphasized that he personally visited the classroom and interacted with the students about all the spheres of school life, which helped him to know the students' challenges, their needs and demands, their feelings and emotions. This shows that interaction, either individually or in group, is the best way to impart care to the target students. It assists in addressing the collective concerns, which convince the group of students that the principal is conscious to fulfill their needs.

Communicating, interacting, inviting, and contacting the immediate stakeholders of the schools in society is another approach to community care. In the process, the stakeholders (parents, civil, political party leaders, etc.) of the school get an opportunity to participate in the social affairs. Asserting the need of caring the community for the school's development, Bibek Pokhrel (male, aged 42), one of the principals, told me that he invited the members of local civil society, representatives of different political parties and consumers' group at local level to participate in the school programs like entrance exam and School Annual Day. The principal also claimed that he personally meets the community people and local political leaders to strengthen his personal and professional relationship with them. According to the principal, such care as a part of his ethical leadership contributes in establishing trust and harmony between the school and the society.

\section{Gravity of Care in TVET Principals}

The case of 'caring' in the part of the principal was not the same in some technical schools in several occasions. I observed that the gravity of caring in the part of some principals was shallow. Describing the status of "caring" of a principal, a student named
Bina BK of ANM stream said: A girl studying in JTA course married a boy studying in the same course in the school. After marriage, they left their studies. The principal did not take this issue into his notice. The principal should have called the boy and the girl and convinced them to study even after their marriage. He should have inspired them to prioritize studies and to marry after completion of study. He should have also consulted their parents to induce them to continue their studies, which was not done. In such a case, the principal needed to be caring but he was not so.

To Bina, administrative care in the part of the principals (in some cases) was weak and repulsive. Therefore, the quality of being caring does not lie equally strong among all the principals under this study. In the above case, the principal lacked the quality of being caring particularly in guiding and reorienting the students who left their studies simply in the name of marriage.

Therefore, care as the part of ethical leadership is very important to bridge the stakeholders of the school. Care in the part of school principals helps to develop an environment where the stakeholders are interlinked by their performances.

\section{Influence of Caring in TVET Schools: An Ongoing Phenomena}

Care in TVET schools is the nurturing attempt by which the principals implant in stakeholders a sense of cooperation, collaboration and support. While describing the nurturing attempts, Noddings (2002) emphasized engaging students in dialogue about moral life, supervising the practice of care, and assisting in their attempts at developing their best selves. In the caring and nurturing of the leadership, all the school staffs including the students are interwoven in a network in which everyone performs their duty independently. Yet there is a close interlink and dependence in terms of cooperation, support and collaboration. The Vedic literature also declares 
that being a leader one needs to be caring and should perform leadership by maintaining harmonious relationship and congenial working environment. For example, Rigved (9-5-9), a collection of hymns written probably during $2^{\text {nd }}$ millennium $\mathrm{BC}$ in classical Sanskrit and known to be a treasure of knowledge declares, "Indurindro brisha harih pavmaan prajapati."

Interpreting the above verse, Misra (2007) says that the person engaged in rearing, cultivating and taking care of the people ought to be possessed of six qualities. For him, Vrisa denotes the quality of being strong, Indra indicates affluence and strength to destroy the enemy, Hariah is for removing the pains and agonies of the people, Pavamanah being pious oneself and making others pious, Induh giving peace and happiness to the people, and Prajapatih cherishing the quality of a preserver of the people to make them joyful.

The above verse is much relevant in the context of school leadership. Following the quality of Indra, the principal as the head of the educational institution requires having the courage to deal with the issues and threats that are likely to hamper the schools' activities and performances. Similarly, as in Induh, the leader needs to perform the activities that maintain peace and happiness to the school stakeholders. The Vrisa in the sense of school activities can be interpreted as being strong enough to handle school activities for the benefit of students. The term Harih can be interpreted in the role of a school's principal for removing pains and suffering of the students. Pavamanah is another term in the aforesaid Vedic verse which asserts that a school leader has to perform his duties as a devotee, ensuring the optimum development of the organization. Remaining with the quality of Prajapatih, the principal needs to ensure preservation, growth and development of the students. These are not only the qualities of school principal, but also are the ways of caring in the school system.

I have elicited a series of assertions from the data obtained from this study findings regarding how care is exhibited in the ethical practices of a school principal. Personal approaches of principals to establish "near and dear" relationships with the instructors, students and community members were observed to be basic and fundamental assumption of care. Personal approach in this context indicates the individual characteristics of principals that comprise the sense of showing concern about the others; openness, clarity and accuracy in dealing with the students, instructors and community members (Starratt, 2011). The principals under this study emphasized listening to the grievances of the concerned students and instructors and also address them with due care as a part of ethics. Austin (2006) has also asserted that core elements of relational ethics (termed as care in this study) are identified as engagement, mutual respect, embodied knowledge, and attention to an interdependent environment. Also, these elements are informed by the concepts of interdependency, relational personhood, authentic dialogue, and the importance of community (p. 136). This idea is very similar to what I explored in TVET schools, that care was communicated in schools by using proper language, actions and behaviors; interacting informally with the students and stakeholders; forgiving the wrong doers and providing them a chance to rectify their wrong behaviors and actions; maintaining an easy, comfortable and effective channel of communication within the school system; and communicating, interacting, inviting and contacting the stakeholders.

\section{Conclusions}

Care is the most indispensable, unavoidable and inevitable part of school leadership in TVET in the sense that it does not only foster the studentsadministration relationship but also strengthens and tends to perfect the congenial relationship between and among all stakeholders such as instructors, students, principal, and other school staff of the schools. This dimension is also very imperative to ensure that leadership in school was welcoming and responsive to the students. Consequently, it lessens the anxiety of the students and helps to bring the 
academic success. This is pertinent as the students of TVET schools are from various family backgrounds, academic performances and anxious of the new environment of the school. Care often tends to lessen the level of anxiety on the part of the students. It ensures the emotional well-being and regulates students' emotions in a right way. In some cases, care becomes the psychosocial tool to handle the complexities with the students and it is communicated through language, actions and behaviors. Informal interaction can also be the part of caring in some occasions. Caring is also used in finding a solution to arguments and disputes in schools. In this regard, the principal uses various approaches to demonstrate his/her ethics of care. The principal maintains an easy, comfortable and effective channel of communication within the school system. Interacting, inviting, and contacting students and other stakeholders are other approaches of maintaining a caring environment in schools. However, depending upon socialization of the principals, caring of each principal differs. As ethics of care is rooted in Vedic tradition, their exposure towards the culture and values contributes to grow their extent of care. The culture and values what they learn differ from individual to individual, they apply their own way of caring which is unique in some occasions. A research or the continuous discourse on the differences can be helpful to each principal of TVET schools to learn from each other and reflect the comparative perspectives in their practices to be the innovative principal of the $21 \mathrm{st}$ century.

\section{References}

Austin, W. (2006). Engagement in contemporary practice: A relational ethics perspective [Special issue]. Texto Contexto Enferm, 15, 135-41. Retrieved from http://www.scielo.br/pdf/tce/v 5nspe/v15nspea15.pdf

Boblin, S. L., Ireland, S., Kirkpatrick, H., \& Robertson, K. (2013). Using Stake's qualitative case study approach to explore implementation of evidence-based practice. Qualitative Health
Research, 23(9), 1267-1275.

Brown, P. A. (2008). A review of the literature on case study research. Canadian Journal for New Scholars in Education, 1(1), 1-13.

Fan, S. C. (2011). Ethics, leadership, ethical leadership: A study of Buddhist and American thoughts (Unpublished doctoral dissertation). College of Education and Organizational Leadership, Organizational Leadership Department, University of La Verne, La Verne.

Gilligan, C. (1982). In a different voice: Psychological theory and women's development. Cambridge, MA: Harvard University Press.

Government of Nepal (GON). (1988). Council for Technical Education and Vocational Training Act, 2045 (1988). Kathmandu, Nepal: Author.

Khanal, G. (2013). TVET policy, 2012: Ambitious or achievable? Technical and Vocational Education Training Development Journal, 13(1), 5-13.

Langlois, L. (2011). The anatomy of ethical leadership: To lead our organizations in a conscientious and authentic manner. Laval, Canada: University of Laval.

Merriam, S. B. (1998). Qualitative research and case study applications in education. San Francisco, CA: Jossey-Bass Publishers.

Misra, N. (2007). Better management and effective leadership. New Delhi, India: Pustak Mahal.

Myers, E. L. (2013). Case study of a male school principal's leadership practices: An exploration of emotion \& the ethic of care (Unpublished doctoral dissertation). The Temple University Graduate Board, Philadelphia, USA.

Noddings, N. (2002). Starting at home: Caring and social policy. Berkeley, CA: University of California Press. 
Phillips, E. M. (1991). Anxiety and oral competence: Classroom dilemma. The French Review, 65(1), $1-14$.

Shapiro, J. P., \& Stefkovich, J. A. (2011). Ethical leadership and decision making in education: Applying theoretical perspectives to complex dilemmas (3rd ed.). New York, NY: Taylor and Francis.

Sharma, T. N. (2006). Connecting technical education and vocational training with employment in Nepal: Current problems and issues. Technical Education and Vocational Training, 1(1), 1-5.

Stake, R. E. (2005). Qualitative case studies. In N. K. Denzin \& Y. S. Lincoln (Eds.), The Sage handbook of qualitative research (3rd ed., pp. 443-466). Thousand Oaks, CA: Sage.

Starratt, R. J. (1991). Building an ethical school: A theory for practice in educational leadership. Educational Administration Quarterly, 2(2), 185 202.

Starratt, R. J. (2011). Refocusing school leadership: Fore grouping human development throughout the work of the school. New York, NY: Routledge.

Vogt, F. (2002). A caring teacher: Explorations into primary school teachers' professional identity and ethic of care. Gender and Education, 14(3), 251-264.

Yin, R. K. (2011). Qualitative research from start to finish. New York, NY: The Guilford Press.

Yin, R. K. (2014). Case study research: Design \& methods. Los Angeles, CA: Sage. 